\title{
Kaposi Sarcoma Still A Problem in Our Hiv Infected Persons: A Site Experience
}

\author{
Isichei M.W ${ }^{1 *}$,A .F. Ale ${ }^{1}$,Peter $\mathrm{S} \mathrm{D}^{1}$, Shilong D J ${ }^{1}$,Misauno A.M ${ }^{1}$,Isichei ${ }^{2}$ C.O. \\ ${ }^{1}$ Department Of Surgery, Jos University Teaching Hospital, Jos Nigeria. Box 745 Jos, 930001. Nigeria \\ ${ }^{2}$ Faith Alive Foundation Jos.
}

\begin{abstract}
Over 70 million people have been infected by the Human Immunodeficiency virus(HIV) worldwide and the Sub-Saharan Africa has the largest population of people living with Human immunodeficiency virus/Acquired immune disease (HIV/AIDS). Nigeria had about 3.3million people living with the disease as at $2015 .^{(1)}$ There is increase risk of AIDS defining and non AIDs defining cancer in infected persons ${ }^{(2)}$ Despite Antiretroviral drugs, Kaposi sarcoma is still common among HIV infected patients in our setting and runs a very aggressive course. We analyzed the spectrum of malignancies among our HIV infected patients to find out how frequent KS is among these patients. This is a prospective data collection of HIV infected patients at two major treatment facilities in Plateau state over a three year period January 2013 to January 2016.A total of 343 participants were enrolled, 184(56.4\%) were males and 159(46.4\%) were females. Majority of reponndants 100(29.1\%) were in the age group 37 - 47years, 286(86.4\%) married and 244(31.1\%) were unemployed. Commonest malignancy found was Kaposi sarcoma(KS) 129(37.6\%). Most of the participants 197(57.43\%) were on first line drug regiment while 146(42.57\%) were on second line. Of those found to have KS, 69(53.49\%), CI: 44.50\%-62.31\% of them were on first line drug regiment while 60(46.51\%), CI: 37.69\%$55.50 \%$ were on second line.Kaposi sarcoma is still a major problem among our HIV infected patients and is a significant factor for increased mortality. There is need for structured surveillance system incorporated into our HIV treatment programs.
\end{abstract}

Keywords: HIV/AIDS, Cancer, Kaposi sarcoma

\section{Introduction}

Over 70 million people have been infected by the Human Immunodeficiency virus(HIV) worldwide and the Sub-Saharan Africa has the largest population of people living with Human immunodeficiency virus/Acquired immune disease (HIV/AIDS). Nigeria had about 3.3million people living with the disease as at $2015 .{ }^{(1)} \mathrm{HIV}$ infection is known to be associated with opportunistic infections which were the main reason for increased morbidity and mortality in infected patients is no longer a threat to life with HAART. ${ }^{(2)}$ There is also increase risk of cancer in infected persons, these cancers could be AIDS defining or non AIDs defining. ${ }^{(3)}$ Studies show that the high risk of cancer among HIV infected persons is due to the damaged immune system. Cancers then became a major problem among these infected persons. ${ }^{(4)}$ The introduction of the Highly Active Antiretroviral Therapy(HAART) has however changed the outlook of HIV infection in the world. The drugs when taken with full adherence can achieving good viral suppression thereby allowing the immune system the opportunity to build up. ${ }^{(5)}$

Kaposi sarcoma, Non Hodgkin's lymphoma and cervical cancer found to be synonymous with HIV infection when present in an infected individual indicate progression to AIDS. These cancer were also regarded as AIDs defining cancers. Of the three cancers, Kaposi sarcoma and Non Hodgkin's lymphoma affect both sexes. Cervical cancer which affect women has been found to occur as a result of Human papiloma virus(HPV) infection was found to be more aggresses in HIV infected women. ${ }^{(6,7)}$ HPV associated cervical cancer is preventable through routine vaccination and is curable when diagnosed early through regular cervical smear or Visual Inspection with Acetic acid(VIA). ${ }^{(8)}$

Kaposi sarcoma(KS) and Non Hodgkin's lymphoma(NHL) on the other hand are not vaccine preventable therefore early diagnosis is very essential. ${ }^{(9)}$ Factors that have been found to be important in the control and reduction in the incidence of KS and NHL among HIV infected patients are high CD4 level, initiation on HAART and early detection. ${ }^{(10,11)}$ Although these cancers are AIDs defining, most infected patients are not aware of the symptoms to expect therefore they do not look out for them despite being at risk. This has lead to very late presentations with poor outcome. Opportunistic infection in the HIV infected is no longer the major cause of mortality but cancers are. ${ }^{(12)}$ Bearing in mind the aggressive nature of the disease among these group of patients, it becomes very pertinent for both the patients and care giver to become more proactive. Most HIV treatment programs do not include cancer screening in our setting. ${ }^{(13)}$ Cervical cancer screening has been emphasized worldwide and the practice has improved over time but this targets only one group among the affected. 
Since the introduction of the combination antiretroviral therapy, the incidence of Kaposi's sarcoma and NHL (especially the cerebral lymphoma) has decreased. ${ }^{(14)}$ The decreasing incidences of most AIDS-associated cancers in persons with AIDS are consistent with improving CD4 counts after HAART introduction. ${ }^{(15)}$ While this may be the case in other parts of the world where incidence/prevalence studies have been done, in our environment there is paucity of knowledge on the cancer incidence before and in the HAART era . There are however site studies that reported a declining incidence of AIDS defining cancers since the introduction of HAART.

Regular follow up on CD4 levels, viral load, drug compliance and screening are necessary to reduce the scourge of KS among our HIV infected patients. We analyzed the spectrum of malignancies among our HIV infected patients to find out how frequent KS is among these patients. This will help us emphasis the need for KS screening. The findings in this study may be useful in useful in developing cancer screening protocol for HIV treatment programs in our country, which can improve early diagnosis and treatment with a better outcome for these patients.

\section{Materials and methods}

This is a prospective data collection of HIV infected patients at two major treatment facilities in Plateau state over a three year period January 2013 to January 2016. The study was approved by the health and ethics committee of the Faith Alive Foundation Jos. Informed written consent was obtained from the subjects to participate in the study. A structured questionnaire was administered to all infected patients who presented with symptoms of a malignancy. They were followed up till histological diagnosis was obtained then referred for definitive treatment at a tertiary center. Data was obtained on Socio demographics, sign and symptoms patient presented with, duration of current disease, duration of HIV status, CD4 count and HAART combination. Specimen for histological diagnosis was obtained using trucut biopsy needle either direct or image guided depending on the site of tumor; at endoscopy and incision biopsy where indicated. All specimen were subjected to histolopathology, all results negative for malignancy or inconclusive were excluded. Data was entered into Microsoft excel and analyzed using Epi info 3:5.3 software for frequency, proportions, mean and standard deviation. Data summary was done using tables and charts for key indicators.

\section{Results}

A total of 343 participants were enrolled, $184(56.4 \%)$ were males and $159(46.4 \%)$ were females. Majority of reponndants $100(29.1 \%)$ were in the age group 37 - 47years, 286(86.4\%) were married and $244(31.1 \%)$ were unemployed. The commonest malignancy found among respondents was Kaposi sarcoma(KS) 129(37.6\%). Most of the participants 197(57.43\%) were on first line drug regiment while 146(42.57\%) were on second line regiment. All on second line were switched from first line. Of those found to have KS, up to 69(53.49\%), CI: $44.50 \%-62.31 \%$ were on first line drug regiment while 60(46.51\%), CI: $37.69 \%-55.50 \%$ were on second line.

\section{Discussion}

The main finding in this study is the high incidence of Kaposi Sarcoma(KS) among the participants despite being on HAART for a mean period of $9.3790 \pm 3.5055$ years. Granted that the incidence of KS has decreased since the HAART era, the HAART compliance must however be optimum to achieve the desired effect. This study is supported by a study reported by Rohner, Eliane et al who found high risk of KS among their participants despite being on Antiretroviral therapy(ART). ${ }^{(16)}$ Acharya, $\mathrm{S}$ et al also found in their study isolated cases of KS among patients with normal CD4 levels. ${ }^{(17)}$ The explanation for this could be that there may be drug compliance issues among the participants. Non compliance creates the environment for development of HIV associated malignancies in infected patients.Most of the participants in our study were on first line HAART for a long time while those on second line were switched to second line only developing resistance to first line. First line HAART combination is Nucleoside/nucleotide reverse transcriptase inhibitors(NRTI) and Nonnucleoside reverse transcriptase inhibitors which is not as effective as Protease inhibitors(PIs) in inhibiting Kaposi sarcoma tumor growth. This finding is supported by Cattelan, A. M el al who reported a reduced incidence and regression of tumor among patients treated with protease inhibitors combination therapy for KS. ${ }^{(18)}$ The reason for the persistence of KS among our study population could be because of the long term use of NRTIs/NNRTI and switching to PIs was done only when participants failed treatment. This scenario represents the favorable milieu for KS to develop in these participants.

There were more males than females in this study. This is similar to the study done by Kagu, M B et al, they found that more males were affected than females ${ }^{(19)}$ Irina $\mathrm{M} D$ et al also reported that predisposing factors for KS are male sex and age above 40 years. ${ }^{(20)}$ Majority of our patients were in the age range 37-47 which falls into the at risk group. This maybe the reason for the male preponderance in our study group. Saka, B in Lome had a contrary view in their study, they found no gender difference in KS among their study population. 


\section{Figures and tables}

Table 2: Type of cancers participants presented with $(\mathrm{n}=343)$

\begin{tabular}{|l|l|l|}
\hline Diagnosis & Frequency & Percent \\
\hline Kaposi sarcoma & 129 & 37.6 \\
\hline Breast cancer & 49 & 14.3 \\
\hline Prostate cancer & 29 & 8.5 \\
\hline Colorectal cancer & 24 & 7.0 \\
\hline Cervical cancer & 16 & 4.7 \\
\hline Non Hodgkin's lymphoma & 13 & 3.8 \\
\hline Soft tissue sarcoma & 11 & 3.2 \\
\hline Squamous cell carcinoma & 10 & 2.9 \\
\hline Hepatocellular carcinoma & 9 & 2.6 \\
\hline Nasopharyngeal & 7 & 2.0 \\
\hline Ovarian cancer & 6 & 1.8 \\
\hline Endometrial cancer & 4 & 1.2 \\
\hline Cancer of the head pancreas & 4 & 1.2 \\
\hline Bladder cancer & 4 & 1.2 \\
\hline Renal cancer & 4 & 1.2 \\
\hline Thyroid gland cancer & 4 & 1.2 \\
\hline Salivary gland tumor & 3 & 0.9 \\
\hline Melanoma & 3 & 0.9 \\
\hline Gastric cancer & 3 & 0.9 \\
\hline Esophageal ca & 3 & 0.9 \\
\hline Testicular tumor & 3 & 0.9 \\
\hline Penile cancer & 2 & 0.6 \\
\hline Bronchogenic cancer & 2 & 0.6 \\
\hline Phylloides & 1 & 0.3 \\
\hline Total & 343 & 100 \\
\hline & &
\end{tabular}

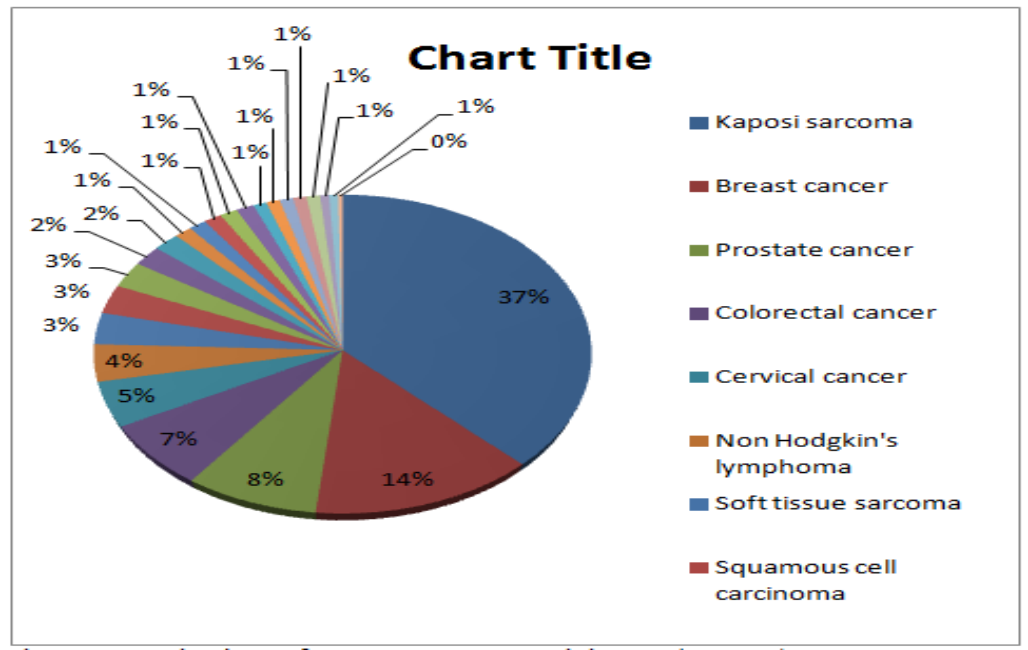

Figure 1: A pie chart of cancers among participants $(n=343)$.

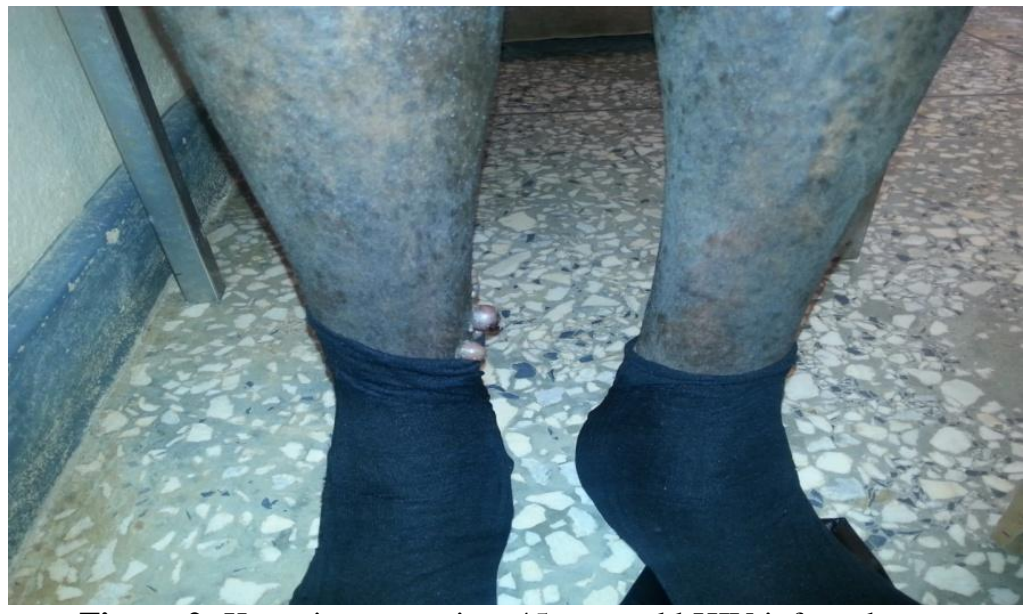

Figure 2: Kaposi sarcoma in a 45 years old HIV infected man 


\section{Conclusion}

Kaposi sarcoma is still a major problem among our HIV infected patients and is a significant factor for increased mortality. There is need for structured surveillance system incorporated into our HIV treatment programs.

\section{Aknowledgement}

We thank Faith alive foundation Jos for partnering with us in this study.

\section{References}

[1]. Global Health Observatory Data 2015

[2]. Buchacz K, Baker RK, Palella FJ, Jr., Chmiel JS, Lichtenstein KA, Novak RM, et al. AIDS-defining opportunistic illnesses in US patients, 1994-2007: a cohort study. AIDS. 2010;24(10):1549-59.

[3]. Patel P, Hanson DL, Sullivan PS, Novak RM, Moorman AC, Tong TC, et al. Incidence of types of cancer among HIV-infected persons compared with the general population in the United States, 1992-2003. Ann Intern Med. 2008;148(10):728-36.

[4]. Oliveira Cobucci RN, Saconato H, Lima PH, Rodrigues HM, Prudencio TL, Junior JE, et al. Comparative incidence of cancer in HIV-AIDS patients and transplant recipients. Cancer epidemiology. 2012;36(2):e69-73.

[5]. Olowookere SA, Fatiregun AA, Adewole IF. Knowledge and attitudes regarding HIV/AIDS and antiretroviral therapy among patients at a Nigerian treatment clinic. J Infect Dev Ctries. 2012;6(11):809-16.

[6]. Abraham AG, Strickler HD, Jing Y, Gange SJ, Sterling TR, Silverberg M, et al. Invasive cervical cancer risk among HIV-infected women: A North American multi-cohort collaboration prospective study. J Acquir Immune Defic Syndr. 2012.

[7]. Agaba PA, Thacher TD, Ekwempu CC, Idoko JA. Cervical dysplasia in Nigerian women infected with HIV. Int J Gynaecol Obstet. 2009; 107(2):99-102.

[8]. Dim CC. Towards improving cervical cancer screening in Nigeria: a review of the basics of cervical neoplasm and cytology. Niger J Clin Pract. 2012;15(3):247-52.

[9]. Chu KM, Mahlangeni G, Swannet S, Ford NP, Boulle A, Van Cutsem G. AIDS-associated Kaposi's sarcoma is linked to advanced disease and high mortality in a primary care HIV programme in South Africa. Journal of the International AIDS Society. 2010;13:23.

[10]. Besson C, Goubar A, Gabarre J, Rozenbaum W, Pialoux G, Chatelet FP, et al. Changes in AIDS-related lymphoma since the era of highly active antiretroviral therapy. Blood. 2001;98(8):2339-44.

[11]. Bonnet F, Balestre E, Thiebaut R, Morlat P, Pellegrin JL, Neau D, et al. Factors associated with the occurrence of AIDS-related non-Hodgkin lymphoma in the era of highly active antiretroviral therapy: Aquitaine Cohort, France. Clinical infectious diseases : an official publication of the Infectious Diseases Society of America. 2006;42(3):411-7.

[12]. Bonnet F, Lewden C, May T, Heripret L, Jougla E, Bevilacqua S, et al. Malignancy-related causes of death in human immunodeficiency virus-infected patients in the era of highly active antiretroviral therapy. Cancer. 2004;101(2):317-24.

[13]. Dim CC, Dim NR, Ezegwui HU, Ikeme AC. An unmet cancer screening need of HIV-positive women in southeastern Nigeria. Medscape J Med. 2009;11(1):19.

[14]. Eltom MA, Jemal A, Mbulaiteye SM, Devesa SS, Biggar RJ. Trends in Kaposi's sarcoma and non-Hodgkin's lymphoma incidence in the United States from 1973 through 1998. Journal of the National Cancer Institute. 2002;94(16):1204-10.

[15]. Ives NJ, Gazzard BG, Easterbrook PJ. The changing pattern of AIDS-defining illnesses with the introduction of highly active antiretroviral therapy (HAART)in a London clinic. The Journal of infection. 2001;42(2):134-9.

[16]. Rohner E, Valeri F, Maskew M, Prozesky H, Rabie H, Garone D, et al. Incidence rate of Kaposi sarcoma in HIV-infected patients on antiretroviral therapy in Southern Africa: a prospective multi-cohort study. Journal of acquired immune deficiency syndromes (1999). 2014;67(5):547-54.

[17]. Acharya S, Ross JD. Kaposi's sarcoma of the recto sigmoid colon in a patient with HIV infection and a high CD4 count. International journal of STD \& AIDS. 2007;18(7):499-500.

[18]. Cattelan AM, Calabro ML, Aversa SML, Zanchetta M, Meneghetti F, De Rossi A, et al. Regression of AIDS-related Kaposi's sarcoma following antiretroviral therapy with protease inhibitors: biological correlates of clinical outcome. European journal of cancer.35(13):1809-15.

[19]. Kagu MB, Nggada HA, Garandawa HI, Askira BH, Durosinmi MA. AIDS-associated Kaposi's sarcoma in Northeastern Nigeria. Singapore medical journal. 2006;47(12):1069-74.

[20]. Irina M.D, Georgeta C.C, Eugen D, Roxana C.C, Sorin R. Risk factors for kaposi sarcoma in HIV infected patients. Acta Medica Mediterranea. 2014, 30: 209 